\title{
The Development of "Friend from Heart" Application based on LINE System to Promote Well-Being of Undergraduate Students of Faculty of Education, Kasetsart University
}

\author{
Manatee Jitanan ${ }^{1}$, Varangkana Somanandana ${ }^{1}$, Sutasinee $\mathrm{Jitanan}^{2}$, Usanee Lalitpasan ${ }^{1} \&$ Sumalee Kham-in ${ }^{3}$ \\ ${ }^{1}$ Faculty of Education, Kasetsart University, Thailand \\ ${ }^{2}$ Faculty of Science, Naresuan University, Thailand \\ ${ }^{3}$ Kasetsart University Laboratory School, Thailand \\ Correspondence: Varangkana Somanandana, Faculty of Education, Kasetsart University Chatuchak, Bangkok \\ 10220, Thailand. Tel: 66-81-867-4239. E-mail: varangkana.s@ku.th
}

Received: March 30, 2021

doi:10.5539/hes.v11n2p215
Accepted: April 30, $2021 \quad$ Online Published: May 6, 2021

URL: https://doi.org/10.5539/hes.v11n2p215

\begin{abstract}
Depression and suicide rates among youths tended to increase. From reviews, many applications and online counseling could reduce depression and anxiety to promote well-being of youths and university students effectively. This study was conducted to develop "Friend from heart" application based on LINE system to promote well-being for undergraduate students of faculty of education, Kasetsart University. The research method included the survey of basic data for developing the application and evaluation of the application by specialists. A total of 72 voluntary students were invited to join an online survey. It was found that most of the students (81.94\%) wanted applications that provide physical health information such as exercise, eating healthy food, and health care. However, about $16.66 \%$ of students needed an application that can speak or listen problems with video calls. Then, researchers took the services that students were interested more than $50 \%$ to develop the applications. It worked through the application, consisting of chatbot, physical health, mental health, and appointment with counselor. The index of item-objective congruence was $0.66-1.00$ with additional specialists commenting that the application had an interesting design with good structure to help students. For ethical approval, it was obtained from the Kasetsart University Research Ethics Committee.
\end{abstract}

Keywords: Application LINE, well-being, undergraduate students, Kasetsart University

\section{Introduction}

In 2017, youth groups aged 20-24 years who was a period of higher education had a suicide rate of 4.94 per 100,000 people. In 2018 , this rate increased to 5.33 per 100,000 people, including information from a phone call for advice that found youth groups called to consult for more mental health issues. In addition, those who called for advice were 14.60 percent of children aged 11-19 years and 20.10 percent of youth aged 20-25 years in 2018 . It found that the most problems in children and youth related to stress, psychiatric problems, love, depression, and family problem. In 2019, there were youth groups aged 11-25 years who continuously called for advice about 33.61 percent of all counselors. Moreover, the department of mental health presented information about depression and suicide rates among youths and undergraduate students which tended to increase. (The department of mental health, 2019). Therefore, youth groups or undergraduate students faced more stress with high risk of suicide.

However, online mental health care services had trend to be more popular. Vongthangsawat (2016) studied the effect of individual existential humanistic online counseling on the wellness of undergraduate students with neuroticism. In this online consultation process, psychologists advised students to review their problems and self-awareness through the conceptual framework of existentialism-humanism. They supported students to choose a new way of life that was consistent with their own. It found that this online counseling was effective for well-being of students with high emotional instability and low emotional instability. Students felt more secure and relieved sadness and anxiety in their lives.

Moreover, Wong, Bonn, Tam \& Wong (2018) compared the face-to face counseling service and online 
counseling among university students. They found that students had a positive attitude with both methods of counseling. The results showed that students with mental health problems were more likely to get online psychological counseling. Therefore, psychological counseling services by using digital media had easier access to the service for university students and may lead to a change in face to face psychological counseling.

In Australia, an online psychological consultancy study was conducted. It found that this counseling services were growing. The psychological counseling methods included email, web-based messaging, video conference, and other forms. The advantages provided flexible service in remote areas, self-protection reduction of clients who had to reveal stories to stranger service providers, low cost, and ability to record advisory services electronically. However, the study did not show that online counseling had more effective than face-to-face counseling. But results reflected effectiveness equally (Chester \& Glass, 2006).

Therefore, mental health with online methods had more popularity and were effective methods. From these reasons, researchers interested to develop the online application based on LINE system that was popular among undergraduate students (Cherdchuchai \& Yenjabok, 2014) for well-being promotion. LINE was a Japanese instant messenger application using for communications on electronic devices such as smartphones, personal computers, and tablet computers. This freeware application was similar to WhatsApp and WeChat. Users could be texting, voice calling, and messaging wherever internet was accessed. In Thailand, LINE was more well-known than WhatsApp and WeChat, so this research developed application enhancing undergraduate students' well-being based on LINE system. The students of the faculty of education, Kasetsart University were selected for this study because they would go to be a teacher which required a good health for taking care of oneself and their students. In this study, the application named "Friend from heart" as a sincere friend who cared of mental health and physical health for well-being.

\section{Literature Review}

The objective of this research was to promote well-being which including physical health and mental health. Therefore, literature review was divided into 2 parts; 1) the relationship between physical health and mental health and 2) application for taking care of physical health and mental health.

World Health Organization defined health as a state of complete physical, mental and social well-being and not merely the absence of disease or infirmity (World Health Organization, 2000). From the definition, it could state that physical health and mental health had relationship. Physical health can be defined as a normal function of the body at all levels; a normal course of biological processes that ensures individual survival and reproduction; a dynamic balance between the body's functions and the environment; participation in social activities and socially useful work; performance of basic social functions; the absence of diseases, painful conditions, and changes; and the body's ability to adjust to the constantly changing conditions of the external environment (Koipysheva, 2018). While mental health was defined as a state of well-being whereby individuals recognize their abilities to cope with the normal stresses of life, work productively and fruitfully, and make a contribution to their communities. (World Health Organization, 2003). Ohrnberger, Fichera \& Sutton (2017) studied the relationship between physical health and mental health. They found that past mental and physical have strong indirect cross effects on current mental and physical health. The key indirect pathways were past cigarette consumption, past physical activity and past social interaction. Similar associations applied for the relationship between past mental health and present physical health.

Promoting physical health and mental health in world 4.0 could use digital technology. So that there were a lot of application program development on a smartphone as a way to help people with mental health problems. For examples, FoodiEat was developed by The National Electronics and Computer Technology Center (NECTEC) (2016) to help users record and receive daily diet and exercise advice in order to use as a guideline in self-care. FoodChoice was developed by Thai Health Promotion Foundation and The National Electronics and Computer Technology Center (NECTEC) (2018) to educate children to perceive understand and aware risk factors in promote health to prevent disease.

Mood Kit was developed by Dorian \& Erhardt (2016) which designed to help people with depression. It based on Cognitive Behavioral Therapy (CBT) as applying effective strategies from psychological experts. MoodKit had integrated tools to help users enhance their emotional activities, identifying and modifying ineffective thoughts, ratings and making mood charts, and creating a notebook to support well-being. The using menu followed: 1) Mood Kit activities for creating positive emotions to reduce negative feelings and enhance well-being. 2) Thought checker for checking their own ideas to enhance positive feelings. 3) Mood Tracker for rating an own mood chart on a daily basis and monitoring the progress of their emotions. 4) Mood Kit Journal for developing self-awareness and attitude. 
Mood Mission was developed by Bakker, Kazantzis, Rickwood \& Rickard (2018) which provided innovative and easily accessible mental health services. The objective of this application was to use CBT strategies for solving anxiety and depression. The CBT-based therapies were provided by trained counselors. The development process consisted of 1) The development of ideas from the conceptual set 2) Empirical evaluation 3) Software and plans for behavior management 4) User feedback and 5) Public launch. The sample group tested the application with mobile application rating scale and provided feedback. It was rated as a higher standard health application than the general entertainment application. Mood Mission had objectives of 1) To help the self-management problem prevention and reduce the risk of emotional and anxiety disorders 2) To be a platform that supports the care of people with low mental health 3) To strengthen the face-to-face psychotherapy for depressed people. Therefore, the Mood Mission application was designed for easy using, strengthened the mental health and well-being of smartphone users in all ages and people with various mental health levels.

Lovejoy, Buch \& Maruthappu (2019) created Artificial intelligence (AI) to look after university students who had mental illness dues to the traumatic event (Post Traumatic Stress Disorder (PTSD) or depression. AI included 1) CBT chatbot: the form of a conversation that transmitted through CBT therapy or Woebot for reducing student depression and anxiety. 2) Meetings for treatment and privacy: a consultation service about mental health and physical health by meeting psychiatrist online which reduced a traveling time and protected privacy.

Bakker et al. (2018) studied the experimentation of 3 mental health-enhancing applications: Mood Mission, Mood Kit, Mood Prism and found the following information: Mood Mission developed 5 activities based on CBT theory called Missions. Each mission developed self-confidence from stress management efforts. Data from 617 users indicated that Mood Mission could improve their mental health. There were 4 main menus: 1) Collecting activities in daily life 2) Checking your own thoughts 3) Taking create mood charts and 4) Recording your own emotions. The activities of the Mood Kit application were developed to enhance mental health. Mood Prism application aimed to check emotions by allowing users to report and review their own emotional status each day. It reflected mental health and feelings all the time. The researcher found that depression and anxiety were reduced if service providers used the Mood Prism to take care of their emotions.

The results showed that the MoodKit and MoodMission applications could significantly reduce depression. There was no application that causes a lot of anxiety. However, the results did not find that all 3 applications were designed to reduce both depression and anxiety during the same period. The using duration affected mental health promotion. In addition, MoodKit and MoodMission could enhance the ability to manage stress with statistical significance. The result from idea management was not found in the Mood Prism application.

For the study of mental health applications in Thailand, the department of mental health has developed an application called Sabai Jai. The objective of this application was to assess the psychological condition of individuals. The application had 5 categories of operation menus which were: 1) Answering questions for giving information about suicide occurring, characteristics of distress, the nature of physical disease that had risk of self-harm, behavior that showed intentions of self-harm, warning signs of suicide problems, including a cognitive video about depression. 2) Screening test by observing oneself or close people who were at risk of self-harm. If it was effective, the application would have suggestions "risk of self-harm" appear below the results of the screening. 3) Talking with someone for adding a list of people who want to talk with by filling the name and phone number 4) Mental health hotline for calling the hotline department of mental health (1323) to consulted with experts via phone call.

According to a study of smart phone applications that promoted mental health in Thailand and abroad, it found that all applications aimed to reduce depression and anxiety as well. There were important menus that include: (1) Providing information about mental illness and ways to prevent stress, (2) Providing self-examination, (3) Using chatbot for basic help, (4) Recording important events in each day which affects emotions of users, (5) Activities to enhance mental health, and (6) Talking with a psychologist/psychiatrist. Therefore, it required effective functions of application menus for developing an application to promote well-being.

For this study, researchers developed the application "Friend from heart" based on LINE system. It was a fast and suitable way to support current lifestyles of students because they used smartphones for various activities routinely. It was an accordance with the social development of the student age in the late teens that they gave importance to have a friend (Engler, 2009). This application would be a friend to help both mental health and physical health simultaneously. The functions followed: (1) Chatbot for chatting automatically and providing basic assistance about physical health and mental health promotion in the form of articles and videos by AI, (2) Live Chat when users wanted to consult with physical health and mental health problems without identity, and 
(3) Call when the user wanted to discuss about mental health and physical health. As for mental health problems, there were experts who graduate with counseling psychology and clinical psychology to help for consultation. For physical health problems, there were experts who graduate in the field related to health education to provide information and help.

\section{Method}

This research used research methodology of research and development. The research objectives was to develop "Friend from heart" application based on LINE system to promote well-being for undergraduate students of faculty of education, Kasetsart University. The operation included the survey of basic data for developing the application and evaluation of the application for the index of item-objective congruence (IOC) from specialists of information technology, mental health, physical health, and research.

\subsection{Participants}

The basic data survey intended to explore the basic needs of undergraduate students. Faculty of Education, Kasetsart University in order to develop the application. The informants were undergraduate students of faculty of education, Kasetsart University in academic year 2019 for 72 students who voluntarily gave data.

\subsection{Research Instruments}

Research instruments were (1) Online basic data questionnaire for developing the application (2) Questionnaire to evaluate the application for specialists, and (3) The "Friend's Heart" application version 1. For ethical approval, it was obtained from the Kasetsart University Research Ethics Committee (study code: KUREC-SS63/069).

\subsection{Data Collection}

Personal contacts were made with 72 undergraduate students of faculty of education, Kasetsart University. Then, students answered the online basic data questionnaire through Google form.

\subsection{Data Analysis}

The data were examined and analyzed by a researcher using statistical software. Descriptive statistics, frequency, and percentage of data were performed.

\section{Results}

The research findings were as follows

\subsection{Result for Developing Application "Friend from Heart"}

From descriptive analysis, a total of 72 target students joined the survey of needs for physical health and mental health services. It was found that most of the students (81.94\%) wanted applications that provide physical health information such as exercise, eating healthy food, and health care. Students (79.16\%) wanted an application that offer mental health information such as ways to relieve stress and stress management. About $61.11 \%$ of students needed applications that offered counseling services via typing, live chat, listening to problems, and solving problems in application. Students (51.38\%) needed application that can talk or listen problems without seeing the face. However, about $16.66 \%$ of students needed an application that can talk or listen problems by seeing the face of the conversation partner. In addition, IOC was 0.66-1.00 with additional specialists commenting that the application had an interesting design with good work structure that was useful for helping students.

\subsection{Application "Friend from Heart" Development Version 1}

From results from the survey, researchers took the services that students were interested more than $50 \%$ to the applications. It worked through the LINE "Friend from Heart" application, consisting of 4 main operations as shown in the figure 1.

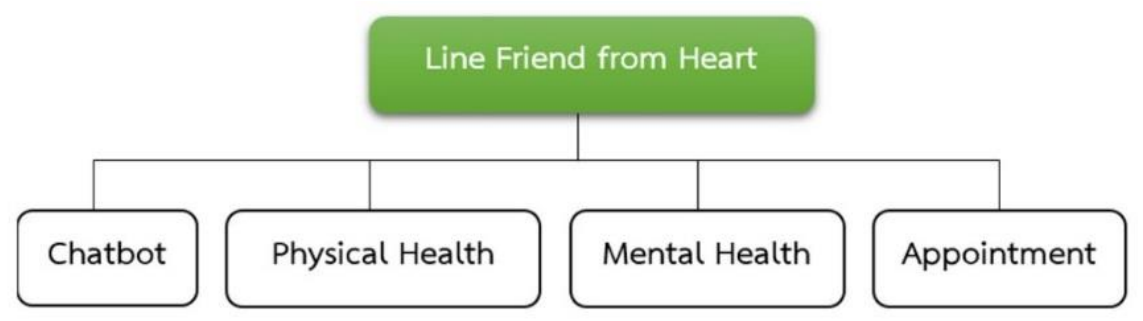

Figure 1. Application "Friend from Heart" based on system 
(1) Chatbot: this operation was an automatic part of answering questions. It provided basic information about mental health and physical health using Dialogflow, a tool for creating a chatbot of Google. This Dialogflow was a machine learning in natural language processing to help for understanding the sentences in the conversation and answer questions according to user needs. As the format specified by Dialogflow, there was flexibility with the sentences that received from users. Without to meet all conditions, it could understand the needs and answers of users. The features of Chatbot could answer texts, images, videos, and stickers of Line, etc. The features were shown in the figure 2 .

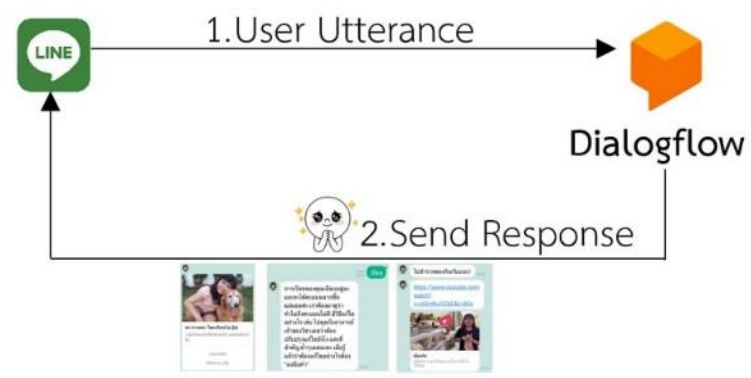

Figure 2. Working between Chatbot and Dialogflow

(2) Physical health: this operation provided information about exercise and eating that affects the body. It presented the information with video clips as shown in the figure 3 .
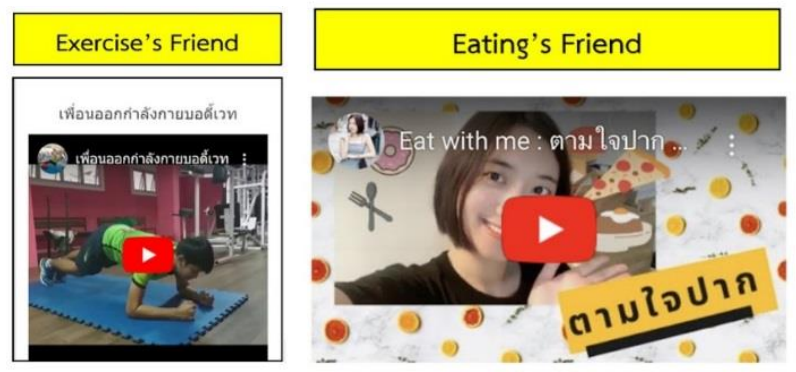

Figure 3. Physical Health's information

(3) Mental health: this operation was the provision of mental health care information in the form of articles and video clips. It provided various insights regarding mental conditions as shown in the figure 4.
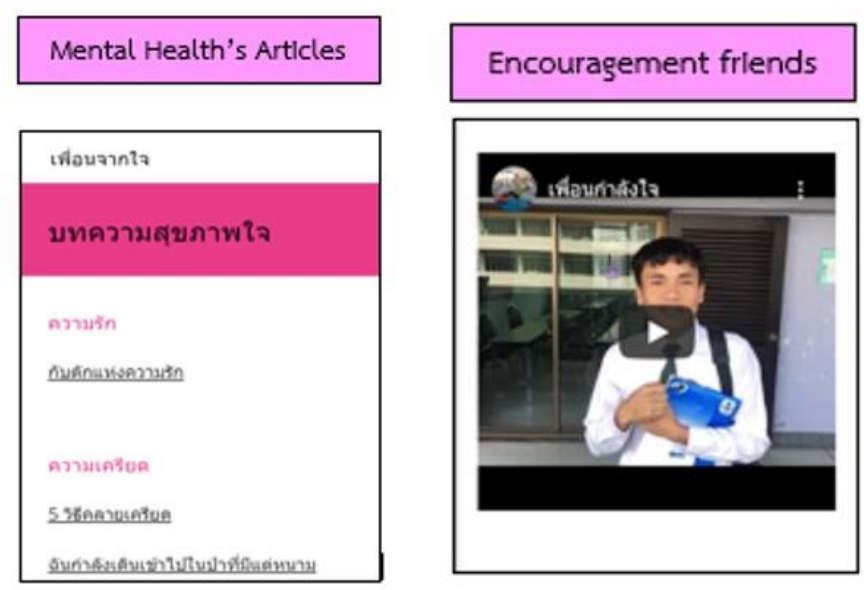

Figure 4. Mental Health's information

(4) The appointment schedule: this operation was a making appointment to talk with a counselor in order to get advice of psychological problems. There were 2 types of chatting. The first type was live chat that can be 
scheduled in response time. The second type was chatting via online telephone with advance appointment. This appointment consisted of booking appointments by users, scheduling appointments by counselors, appointing reminders, and canceling appointment.

(4.1) Booking appointment times by users: this function made appointment for counseling from users who used the application as shown in the process of figure 5.

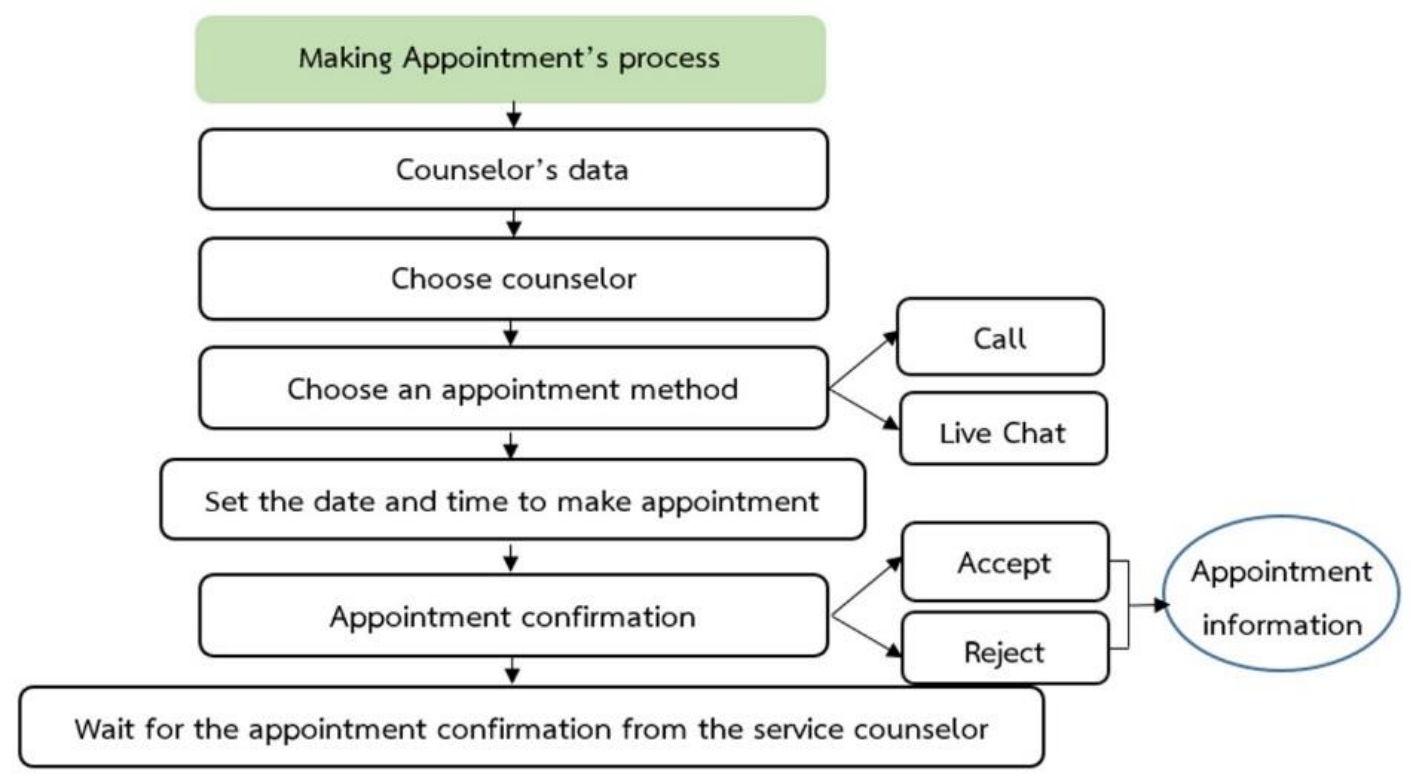

Figure 5. Appointment's process

- Step 1 : User typed "appointment" or selected menu "Schedule". Then, the "Appointment schedule" appeared on the application.

- Step 2 : The system displayed the counselor information and buttons for choosing a counselor to make an appointment (figure 6). Counselor information included name-surname, introduction information, calendar showing the date and time that user could make an appointment (figure 7).

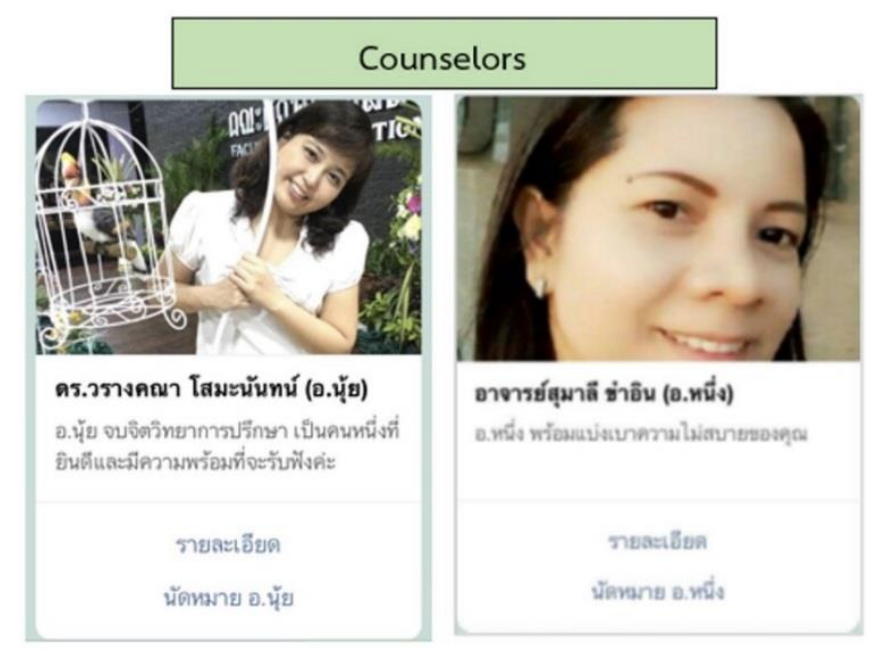

Figure 6. Counselor's selection menu 


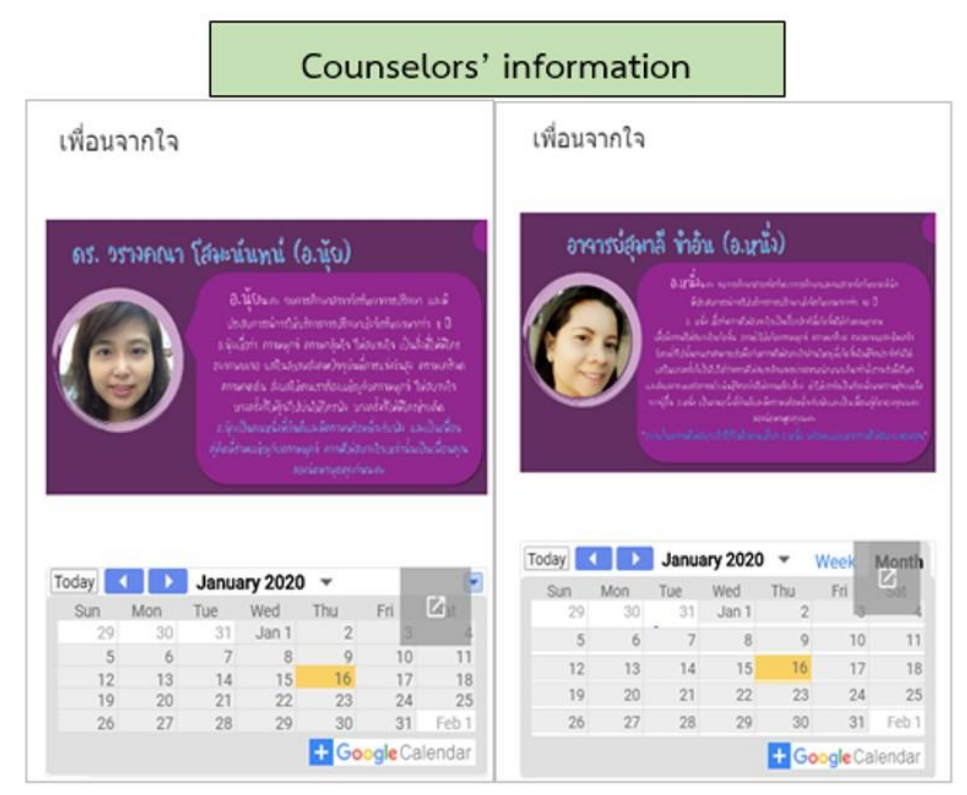

Figure 7. Counselor's data

- $\quad$ Step 3 : User selected a counselor by pressing the button "Appointment with Teacher Nui" or "Appointment with Teacher Nueng."

- Step 4 : User chose an appointment method by typing the word "Chat" or "Call". Chat was an online messaging chat (interactive). Call was a conversation through online telephone channel.

- $\quad$ Step 5 : User set the date and time of the appointment. It was in the form of "This Saturday" "Next Sunday" or set to a date, month, year, such as January 31 2020. Time was in the form of HH: MM am / pm or HH: MM such as 8.00 a.m., 18.00 .

- Step 6: User confirmed the appointment. Then, the system displayed the information of the appointment which includes name of counselor, appointment type, date and time of appointment. The system allowed user to confirm the correctness by answering "Yes" or "No" If answering "Yes", the appointment information sent to the system to wait for confirmation from the counselor. If answering "No", user could start a new appointment.

- Step 7 : User waited for the appointment confirmation from the counselor. There would be a reply from the system once the counselor confirmed the appointment.

(4.2) Schedule management by counselor: this function could manage the details of the appointment (figure 8) which consists of 3 parts as follows:

- Part 1: Scheduling appointments allowed the counselor to determine the day and time for the consultation. So, users could check an available time for an appointment.

- Part 2: Appointment confirmation allowed the counselor to confirm or reject appointments from users. The system would sent the appointment results to Line application of users. After counselor confirmed, the appointment would appear on the Google calendar in the system.

- Part 3: Appointment information display allowed the counselor to see the appointment schedule of user in the format of Google calendar. 


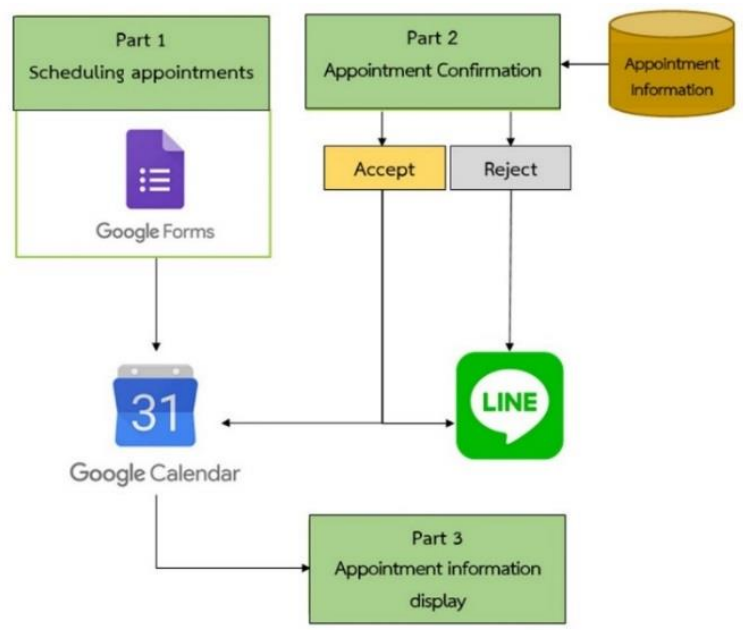

Figure 8. Schedule appointments by a counselor

(4.3) Appointment reminders: this function was a notification for an hour before the appointment. The notification was sent to the user through the application for preparation of both parties before discussion. In which the counselor would contact with the appointed user. Appointment notification was retrieved information from the individual counselor's Google calendar.

(4.4) Cancellation of an appointment: this function was used when user needed to cancel the appointment as following steps: (1) Typed the word "cancel appointment", (2) Typed the name of the appointed counselor, (3) Typed "date and time" for canceling, (4) Confirmed cancellation. Then, the appointment had been deleted.

\section{Discussion}

The development of "Friend from Heart" application had 3 main operations including providing mental health information, providing physical health information, and providing counseling services. These operations were consistent with the study of applications that care for mental health in foreign countries. It found that most developed applications provided mental health information (Dorian and Erhardt, 2016; Bakker et al., 2018; Lovejoy et al., 2019). As well as some application designed to provide psychological counseling services including a comfortable application developed by the Department of Mental Health of Thailand. This application had a function to be able to discuss mental health problems (Department of Mental Health, 2019). Therefore, the "Friend from Heart" application was comprehensive and covered knowledge about mental health and physical health including psychological counseling services with the idea of being a sincere friend. The application suited with the age of students in the late teens who focus mainly on their friends (Engler, 2009).

\section{Conclusion and Recommendation}

In conclusion, LINE "Friend from Heart" application was developed to provide information about physical health and mental health with mental health counseling for undergraduate students under the concept of friendship. There were 3 types of services including Chatbot, Live Chat, and Call. However, this research did not have the function of checking one's own emotions like foreign applications which may be the part for researchers to develop further.

\section{References}

Bakker, D., Kazantzis, N., Rickwood, D., \& Rickard, N. (2018). Development and pilot evaluation of smartphone-delivered cognitive behavior therapy strategies for mood- and anxiety-related problems: MoodMission. Cognitive and Behavioral Practice, 25(4), 496-514. https://doi.org/10.1016/j.cbpra.2018.07.002

Cherdchuchai, P., \& Yenjabok, P. (2014). Usage Behavior of "LINE" Social Application of Which Affects Complacency and Utalization: Sripatum University Undergraduate. Bangkok: Sripatum University.

Chester, A., \& Glass, C. A. (2006). Online counselling: A descriptive analysis of therapy services on the internet. British Journal of Guidance \& Counselling, 34(2), 145-160. https://doi.org/10.1080/03069880600583170

Dorian, E., \& Erhardt, D. (2015). MoodKit / Moodnotes App Developers Offer New Year's Resolution Tips for Well- Being. Retrieved from 
http://www.thriveport.com/blog/files/ff2e9475ef87984912d089acdbea40f5-8.html

Engler, B. (2009). Personality theories (8th ed.). Australia: Wadsworth/Cengage Learning. Grove, Calif: Brooks/Cole.

Koipysheva, E. (2018). Physical Health (Definition, Semantic Content, Study Prospects. In RPTSS 2018 International Conference on Research Paradigms Transformation in Social Science. London: The European Proceedings of Social \& Behavioural Sciences. pp. 601-605. https://doi.org/10.15405/epsbs.2018.12.73

Lovejoy, C. A., Buch, V., \& Maruthappu, M. (2019). Technology and mental health: The role of artificial intelligence. European Psychiatry, 55(13), 1-3. https://doi.org/10.1016/j.eurpsy.2018.08.004

Ohrnberger, J., Fichera, E., \& Sutton, M. (2017). The relationship between physical and mental health: A mediation analysis. Social Science \& Medicine, 195(C), 42-49. https://doi.org/10.1016/j.socscimed.2017.11.008

The department of mental health. (2019). Department of Mental Health cares for Thai children with depression. Suggestions for those around to listen and understand. Retrieved from http://www.prdmh.com

The National Electronics and Computer Technology Center [NECTEC]. (2016). FoodiEat. Retrieved from https://www.nectec.or.th/innovation/innovation-mobile-application/foodieat.html

The National Electronics and Computer Technology Center [NECTEC]. (2018). FoodChoice. Retrieved from https://www.nectec.or.th/innovation/innovation-mobile-application/foodchoice.html

Vongtangswad, S. (2016). The Effect of Individual Existential-Humanistic Online Counseling on Wellness of Undergraduates with Neuroticism. Bangkok: Chulalongkorn University.

Wong, K. P., Bonn, G., Tam, C. L., \& Wong, C. P. (2018). Preferences for online and/or face-to-face counseling among university students in Malaysia. Frontiers in Psychology, 9(64), 1-5. https://doi.org/10.3389/fpsyg.2018.00064

World Health Organization [WHO]. (2000). The world health report 2000: health systems: improving performance. Geneva: World Health Organization.

World Health Organization [WHO]. (2003). Investing in mental health. Geneva: World Health Organization.

\section{Copyrights}

Copyright for this article is retained by the author(s), with first publication rights granted to the journal.

This is an open-access article distributed under the terms and conditions of the Creative Commons Attribution license (http://creativecommons.org/licenses/by/4.0/). 